\title{
Activation Processes and Polyethylene Formation on a Phillips Model Catalyst Studied by Laser Ablation, Laser Desorption, and Static Secondary Ion Mass Spectrometry
}

\author{
Frédéric Aubriet* and Jean-François Muller \\ Laboratoire de Spectrométrie de Masse et de Chimie Laser, Université Paul Verlaine-Metz, Metz, France
}

\section{Claude Poleunis and Patrick Bertrand}

Unité de physico-chimie et de physique des matériaux, Université catholique de Louvain, Louvain-la-Neuve, Belgium

\author{
Pascal G. Di Croce and Paul Grange \\ Unité de catalyse et de chimie des matériaux divisés, Université catholique de Louvain, Louvain-la-Neuve, \\ Belgium
}

\begin{abstract}
Since the discovery of the Phillips catalysts, there still is much uncertainty concerning their activation, their molecular structure, the nature of the active chromium sites, and the polymerization mechanisms. Surface techniques are not easy to be used for such study according to the nonconductive behavior of the support. Therefore, model Phillips catalyst is elaborated by spin coating a trivalent chromium precursor on a silicon wafer. The surface characterization of this model catalyst is conducted by laser ablation mass spectrometry (LA-MS), laser desorption/ionization mass spectrometry (LDI-MS), and static secondary ion mass spectrometry (s-SIMS), at different steps of its preparation. To validate our approach, a comparison is also made between the model and the real Philips catalyst. Moreover, the model catalyst efficiency for polyethylene synthesis is evaluated and allows us to discuss the validity of the mechanisms previously proposed to explain the catalytic process. The characterization of Phillips model catalyst by mass spectrometry allows us to better understand the activation processes of such catalyst. Depending on the activation temperature, chromium oxide species are formed and anchored at the support surface. They consist mainly in mono-chromium sites at high temperature. The chromium valence is hexavalent. This model catalyst is active for the polymerization of ethylene. A pseudo-oligomer molecular weight distribution is observed by LA-MS, whereas s-SIMS allows us to elucidate the anchorage of the polymer at activate chromium surface sites. (J Am Soc Mass Spectrom 2006, 17, 406-414) (C) 2006 American Society for Mass Spectrometry
\end{abstract}

$\mathrm{C}$ hromium compounds are involved in many industrial catalysts used to perform hydrogenation, dehydrogenation, isomerization, or polymerization of organic compounds. The most important industrial application is the Phillips $\mathrm{Cr} / \mathrm{SiO}_{2}$ catalyst for the production of polyethylene [1-3]. Industrial Phillips catalyst is typically prepared by impregnation of a high surface area material, e.g., silica, with an aqueous solution of a hexavalent $\mathrm{Cr}(\mathrm{VI})$ - or a trivalent $\mathrm{Cr}(\mathrm{III})$ -

Published online February 3, 2006

This article is dedicated to Professor Paul Grange (1943-2003).

Address reprint requests to Dr. Frédéric Aubriet, Laboratoire de Spectrométrie de Masse et de Chimie Laser, Université de Paul Verlaine-Metz 1, Boulevard Arago, F-57078 Metz Technopole 2000 Cedex 03, France. E-mail: aubriet@univ-metz.fr

* Also at Unité de physico-chimie et de physique des matériaux, Université catholique de Louvain, Croix du Sud 1, B-1348 Louvain-la-Neuve, Belgium. precursor salt. After activation and eventually a reduction step, heterogeneous systems consisting of small particles (active sites) hidden inside the pores of inorganic supports are obtained. A $0.2-1.0 \mathrm{Cr}$ wt.\% loading of the catalyst is commonly attained. However, only a small portion of anchored chromium is active for polymerization. In spite of its interest, Phillips catalyst is not fully understood to date. A general review dealing with the preparation, the activation, the structure, the ethylene polymerization mechanism, and the characterization of $\mathrm{Cr} / \mathrm{SiO}_{2}$ catalyst has been recently published [4]. To improve the catalyst, the authors underline the need of a better understanding of the active site formation and of the catalytic process. Although numerous investigations were performed since the discovery of the Phillips catalysts, much uncertainty still exists concerning their activation [5], their molecular structure [6], the 
nature of the active chromium sites [7], and the polymerization mechanisms [8] (kinetic control, activity). The growth of polymer at the catalyst surface is poorly understood to date [9].

Since the supports typically used for the anchorage of Phillips catalyst are nonconductive, their analysis by commonly used surface techniques is not easy. To overcome this problem, model Phillips catalysts for ethylene polymerization have been prepared and investigated. Based on ion-scattering experiments, Thüne et al. [10-12] proposed a description of the activation process of a model Phillips catalyst that is active for ethylene polymerization. Loos et al. [13] and Thüne et al. [11] determined by AFM the morphology of the crystallized polymer layers produced at different polymerization times. A model Phillips catalyst has been elaborated in our group by spin coating a trivalent chromium precursor (chromium acetylacetonate noted here $\mathrm{Cr}(\mathrm{acac})_{3}$ ) on a silicon wafer. Preliminary results of its characterization by different surface and mass spectrometry techniques have already been published [14, 15]. Information on the catalyst activation and the ethylene polymerization efficiency has been obtained.

This paper deals with the surface characterization of this model catalyst at the different steps of its preparation. A comparison is also made between the model and the real Philips catalyst. For that purpose, mass spectrometry techniques are used. They consist of laser ablation mass spectrometry (LA-MS), laser desorption/ ionization mass spectrometry (LDI-MS), and static secondary ion mass spectrometry (s-SIMS). Indeed, s-SIMS as well as LDI-MS appear to be well suited to characterize both precursor and chromium oxygenated species present at the surface of model catalyst. Prior works demonstrated the ability of both techniques to characterize in positive detection mode metal acetylacetonate, and especially chromium one by s-SIMS [16, 17] or LDI-MS [16, 18, 19]. Generally, associations between chromium atoms and various amounts of acetylacetonate ligands $\mathrm{Cr}_{\mathrm{x}}(\mathrm{acac})_{\mathrm{y}}{ }^{+}$are observed. Oxide chromium compounds have been also extensively studied, especially by our group; in that case $\mathrm{Cr}_{\mathrm{x}} \mathrm{O}_{\mathrm{y}}{ }^{ \pm}$cluster ions are detected [20, 21]. Moreover, the model catalyst efficiency for polyethylene synthesis is evaluated. Finally, the characterization of the catalyst surface after polymerization allows us to discuss the validity of the mechanisms previously proposed to explain the catalytic process [4].

\section{Experimental}

\section{Sample Preparation}

The different steps for the model catalyst elaboration consist of the support preparation, its impregnation by the catalyst precursor, and its activation. P-type silicon wafers with (100) surface orientation are used as substrates and are pretreated as follows [10]. Square pieces $\left(1.5 \times 1.5 \mathrm{~cm}^{2}\right)$ of wafers are calcinated at $750{ }^{\circ} \mathrm{C}$ in air for $24 \mathrm{~h}$ to present an amorphous $\mathrm{SiO}_{2}$ surface layer. Then, they are cleaned at $70{ }^{\circ} \mathrm{C}$ with a mixture of $\mathrm{H}_{2} \mathrm{O}_{2}$ $(30 \%)$ and $\mathrm{NH}_{4} \mathrm{OH}(30 \%)$ in a ratio $3 / 2 \mathrm{vol} / \mathrm{vol}$. After several rinses with milli-Q water (HPLC grade produced by a Milli-Q plus system from Millipore, Molsheim, France), the wafers are placed for $30 \mathrm{~min}$ in boiling water, to hydroxylize the surface. They are kept in water until the impregnation process to avoid contamination from the atmosphere.

Spin coating is performed in air with a CT60 spin coater from Karl Suss Technique (Grove City, PA). The water film is first removed by spinning $3 \mathrm{~min}$ at 5000 $\mathrm{rpm}$. Then the wafers are totally covered with three drops of the $\mathrm{Cr}(\mathrm{acac})_{3} \quad\left(\mathrm{C}_{15} \mathrm{H}_{21} \mathrm{CrO}_{6}\right.$ for synthesis, (Merck, Darmstadt, Germany) precursor solution in THF (99\%, Aldrich, Steinheim, Germany) at different concentrations $\left(10^{-1}, 10^{-2}, 10^{-3}, 10^{-4}\right.$, and $10^{-5}$ mol. $\mathrm{L}^{-1}$ ). Unless stated otherwise, the spinning process is conducted at $3000 \mathrm{rpm}$ during $60 \mathrm{~s}$. The evaporation of the solvent is monitored by the disappearance of the Newton rings, which, in all cases, occurs before the end of the spinning.

The spin coated samples are activated in a quartz reactor, under a $30 \mathrm{ml} / \mathrm{min}$ flow of dry air $(99.98 \%$, Indugas, Enschede, The Netherlands) purified over molecular sieves (3 A, Alltech, Deerfield, IL). The temperature is increased gradually in $100{ }^{\circ} \mathrm{C}$ increments at a rate of $10^{\circ} \mathrm{C} / \mathrm{min}$. After each step, the reactor is thermally stabilized by keeping the temperature constant for $1 \mathrm{~h}$. The final activation is done at $650^{\circ} \mathrm{C}$ during $6 \mathrm{~h}$, as performed in the industrial activation process. The activated wafers are then used in a polymerization reaction. This is carried out at $160^{\circ} \mathrm{C}$ during $\sim 30 \mathrm{~min}$ in 2 bar ethylene $(30 \mathrm{ml} / \mathrm{min})$, purified over molecular sieves. These reaction conditions are chosen to reduce the induction period appearing before the starting of the polymerization process. The reaction is then stopped by switching to purified He flow (30 $\mathrm{ml} / \mathrm{min}$ ) at $160^{\circ} \mathrm{C}$ for $2 \mathrm{~h}$, before cooling the reactor to room temperature.

The real Phillips catalyst is prepared with a protocol similar to those used for the model catalyst. After impregnation, a violet powder is obtained and becomes orange-yellow after activation. To reproduce industrial Phillips catalyst preparation, a reduction step is added. The reduction is conducted in hydrogen atmosphere at $350{ }^{\circ} \mathrm{C}$ for $2 \mathrm{~h}$. Under these conditions, catalyst develops a green color.

\section{Secondary Ion Time of Flight Mass Spectrometer}

Positive and negative static (s-)SIMS measurements are performed with a TOF-SIMS spectrometer from PhiEvans (Redwood, CA). The sample is bombarded with a pulsed primary $15 \mathrm{keV}^{69} \mathrm{Ga}^{+}$liquid metal ion beam. The secondary ions are accelerated to $3 \mathrm{keV}$ before being deflected $270^{\circ}$ by three electrostatic hemispherical analyzers (TRIFT). To increase the detection efficiency of ions at high $\mathrm{m} / \mathrm{z}$ values, a post-acceleration of $7 \mathrm{keV}$ 
is applied at the detector entry. A 800 pA DC primary ion is pulsed at a $11 \mathrm{kHz}$ repetition rate with a pulse width of $22 \mathrm{~ns}$, finally electrodynamically bunched down to $1 \mathrm{~ns}$ to increase mass resolution, and rastered over a $130 \times 130 \mu^{2}$ surface area. With a data acquisition of $5 \mathrm{~min}$, the total fluence is $\sim 2 \times 10^{12}$ ${ }^{69} \mathrm{Ga}^{+} / \mathrm{cm}^{2}$ ensuring static conditions. Charging effects are compensated by means of a $24 \mathrm{eV}$ pulsed electron flood gun. Moreover, a stainless steel grid (nonmagnetic) with $2 \mathrm{~mm}$ mesh is put onto the sample surface to prevent variation of the surface potential. Under these experimental conditions, the mass resolution $(\mathrm{m} / \Delta \mathrm{m})$ is about 2800 at $m / z$ 100. Two kinds of experiments are conducted: (1) with or (2) without a presputter cleaning of the surface with an ion fluence of $10^{14}$ or $6 \times 10^{14}$ ${ }^{69} \mathrm{Ga}^{+} / \mathrm{cm}^{2}$ before the analysis. The presputter cleaning aims at removing the organic contaminants of the sample surface. To check the reproducibility, the experiments are repeated four times on different areas of the same sample, and are duplicated with another sample prepared independently. The relative intensity $I_{i}$ of a given ion $i$ is the ratio $I_{i} / \Sigma I_{i}$ where $\Sigma I_{i}$ is the sum of all the ion intensities in the spectrum. In contrast to ion abundance, relative intensity allows us to evaluate the relative distribution of expelled species in the gas phase, which are highly correlated with their distribution at the sample surface in s-SIMS experiments.

SIMS imaging is also used to provide information on the surface morphology of model catalyst support after the $\mathrm{Cr}(\mathrm{acac})_{3}$ solution spin-coating. The chemical images have been acquired in both positive and negative detection modes. However, only positive ion results are specifically detailed in this paper. For the TOF-SIMS images $(256 \times 256$ pixels), the beam was rastered over sample areas of $190 \times 190 \mu^{2}$ for $1800 \mathrm{~s}$, which corresponds to projectile fluence close to $10^{12}$ ions $/ \mathrm{cm}^{2}$.

\section{Laser Microprobe Fourier Transform Ion Cyclotron Resonance Mass Spectrometer}

The analyses are performed with a laser microprobe FTICR mass spectrometer that has been described in detail elsewhere [22]. This instrument is a modified, differentially pumped, dual-cell Nicolet Instrument FTMS 2000 (Finnigan FT/MS, now named ThermoElectron, San Jose, CA) operated with a $3.04 \mathrm{~T}$ magnetic field and coupled to a reflection laser interface. The viewing system, using an inverted Cassegrain optics design, allows the visualization of the sample with a 300-fold magnification. A sample holder fitted with motorized micromanipulators allows us to move the sample along the three spatial directions with a spatial accuracy of less than $10 \mu \mathrm{m}$.

A dye laser (TDL-90, Quantel, Les Ulis, Cedex, France) is used for the desorption/ionization process. Rhodamine-590 (Exciton distributed by Optilas, Evry, France) is dissolved in methanol and fluoresces in the $550-590 \mathrm{~nm}$ range when it is pumped with the second- harmonic of a Nd:YAG laser at $532 \mathrm{~nm}$ (Brillant B, Quantel). An optical grating coupled to the laser oscillator cavity allows us to select the $567.2 \pm 0.1 \mathrm{~nm}$ wavelength. The laser energy is increased by a twostage amplifier system with a frequency doubling performed by a KDP crystal. The wavelength of the resulting laser beam is $283.6 \mathrm{~nm}$ with pulse duration of $4.3 \mathrm{~ns}$. The diameter of the laser beam on the sample (placed inside the source cell, just in front of the source trap plate and kept at a ground potential) can be adjusted from five to several hundred micrometers by means of the internal lens and an external, adjustable telescope. This corresponds to a power density ranging from $10^{6}$ to $4 \times 10^{10} \mathrm{~W} . \mathrm{cm}^{-2}$. The experiment sequence used for these analyses is the following. The ions are formed by laser ablation in the source cell (residual pressure $\sim 10^{-6}$ $\mathrm{Pa}$ ). During the ionization event, the conductance limit plate between the two cells and the source trap plate is fixed at a trapping potential of typically $2 \mathrm{~V}(-2 \mathrm{~V}$ in negative detection mode) or at a lower potential in some particular cases (down to $0.25 \mathrm{~V}$ ). A variable delay period follows, during which time ion/molecule reactions could occur. Ions are then excited by a frequency excitation chirp and the resulting image current is detected, amplified, digitized, apodized (BlackmanHarris, three-terms) and Fourier-transformed to produce a mass spectrum.

For the acquisition of each FTICR mass spectrum, one hundred laser shots are fired on different surface spots. This is required to obtain an acceptable reproducibility of the ion relative intensity. To analyze a fresh surface at each laser shot, the sample is moved continuously in $\mathrm{x}$ and $\mathrm{y}$ directions during the experiment with motorized micromanipulators. The assignment of the ion composition is obtained by measuring the exact mass, after calibration and identification of the isotopic distribution. To compare the results, a normalization procedure is used. The relative intensity $\mathrm{I}_{\mathrm{i}}$ of each ion is the ratio $I_{i} / \Sigma I_{i}$ where $\Sigma I_{i}$ is the sum of all ion intensities in the spectrum.

\section{Laser Desorption Time of Flight Mass Spectrometer}

The laser desorption mass spectra are obtained with a Bruker Reflex IV Maldi-TOF instrument (Bruker-Franzen Analytik GmbH, Bremen, Germany) equipped with a delayed extraction. Ionization is produced by a nitrogen laser $(\lambda=337 \mathrm{~nm}$, pulse duration: $3 \mathrm{~ns}$, output energy: $400 \mu \mathrm{J}$, repetition rate: $5 \mathrm{~Hz}$ ). The laser diameter is $\sim 30 \mu \mathrm{m}$. The laser fluence can be varied from 22 to $540 \mathrm{~mJ} / \mathrm{cm}^{2}$ by means of an attenuator, and is typically kept in our experiments at $190 \mathrm{~mJ} / \mathrm{cm}^{2}$, i.e., $\sim 6.3 \times 10^{7}$ $\mathrm{W} / \mathrm{cm}^{2}$ laser irradiance. The mass spectrometer is operated in the reflectron mode at a total acceleration voltage of $20 \mathrm{kV}$ and a reflecting voltage of $23 \mathrm{kV}$. A delay time of $200 \mathrm{~ns}$ is used before ion extraction. The acquisition of mass spectra in the $0-3120 \mathrm{~m} / \mathrm{z}$ mass 

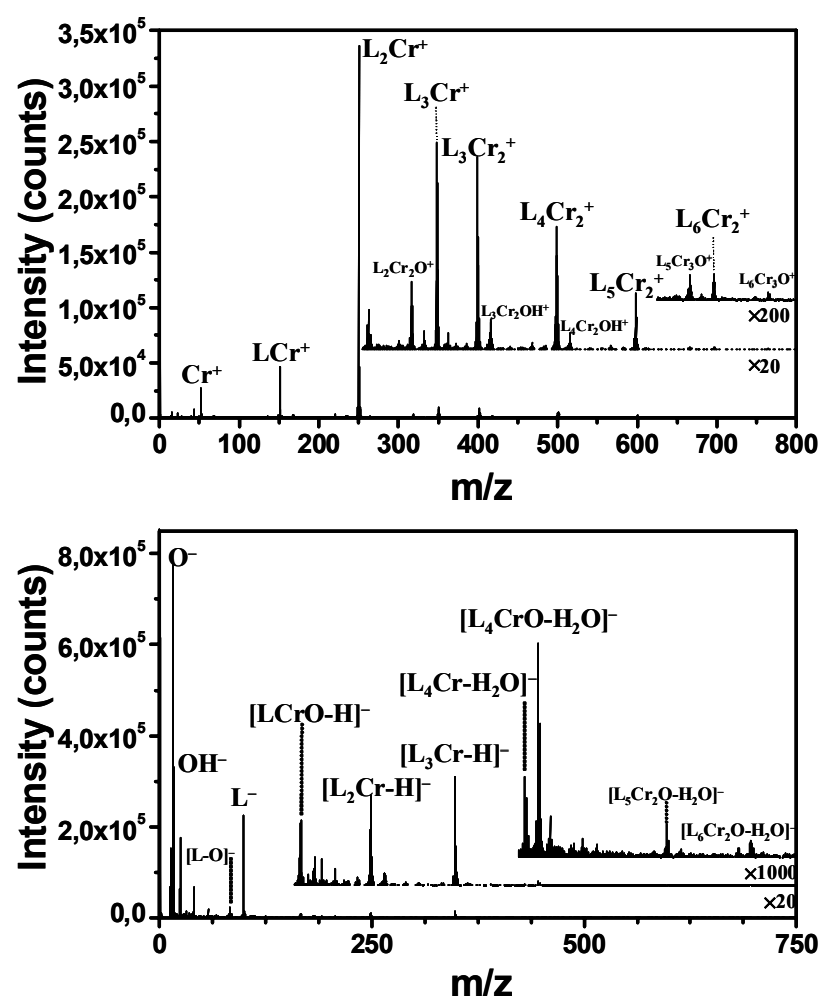

Figure 1. Positive (top) and negative (bottom) $\mathrm{Cr}(\mathrm{acac})_{3}$ TOFSIMS fingerprints. A $10^{-3} \mathrm{~mol} / \mathrm{L}$ precursor concentration was used. $\mathrm{L}=$ acac.

range requires the accumulation of one hundred laser shots on different places of the same sample. The ion molecular composition assignment is obtained after an external calibration performed with polyethylene glycol $600 \mathrm{Na}^{+}$and $\mathrm{K}^{+}$cationized ions. Measurements are conducted without matrix.

\section{Results and Discussion}

Results obtained in the preparation and activation are presented followed by the characterization of model catalyst surface by s-SIMS and LDI-TOF-MS. Finally, the impregnation, activation, and reduction steps required to prepare a real Phillips catalyst is examined in the last section.

\section{Preparation of Model Catalyst}

After $\mathrm{Cr}$ (acac) $)_{3}$ spin-coating, the substrate is investigated by TOF-SIMS in both ion polarities. Figure 1 shows the positive and negative TOF-SIMS spectra of the impregnated substrate with a $10^{-3}$ mol.L ${ }^{-1}$ $\mathrm{Cr}(\mathrm{acac})_{3}$ solution. Whatever the ion mode, secondary ions linked to the $\mathrm{Cr}(\mathrm{acac})_{3}$ precursor are emitted from the surface by the primary ion bombardment. They consist mainly in the association of acac ligands (noted $\mathrm{L}$ in the mass spectra) with various amounts of chromium atoms. Large cations or anions up to $m / z 750$ are observed. In addition to these species, the addition of an oxygen atom to the $\mathrm{L}_{\mathrm{n}} \mathrm{Cr}_{\mathrm{m}}{ }^{+}$ions is observed in the positive detection mode. For the negative ions, the elimination of a hydrogen atom or of a water molecule from $\mathrm{L}_{\mathrm{n}} \mathrm{Cr}_{\mathrm{m}}{ }^{-}$anions is also evidenced. The acac ligand is also observed as a negative ion.

S-SIMS results are very similar to the LA/LDIFTICRMS data reported in a previous publication [15], although smaller ions are detected with LA/LDI-FTICRMS. However, some poor abundant cations are also detected after laser irradiation, which are associated with the loss or the attachment of a water molecule. As an example, $\left[\mathrm{Cr}_{2}(\text { acac })_{2}-\mathrm{H}_{2} \mathrm{O}-\mathrm{H}\right]^{+}$and $\left[\mathrm{Cr}_{2}(\text { acac })_{2}+\right.$ $\left.\mathrm{H}_{2} \mathrm{O}-\mathrm{H}\right]^{+}$are detected at $m / z 283$ and 319, respectively. The observed behavior of $\mathrm{Cr}(\mathrm{acac})_{3}$ impregnated substrate in positive detection mode is similar to what was previously observed by Matsumoto et al. [19]. Moreover, s-SIMS results obtained with $\mathrm{Cr}(\mathrm{acac})_{3}$ on silicon wafer are very close to what was previously observed with other sampling methodologies [16, 17]. Consequently, sample preparation appears to not significantly modify the detection of $\mathrm{Cr}(\mathrm{acac})_{3}$ species by s-SIMS.

Figure 2 presents the TOF-SIMS images of the impregnated support for two spin coating concentrations of the $\mathrm{Cr}(\text { acac })_{3}$ solution: $10^{-1}$ and $10^{-3}$ mol.L ${ }^{-1}$. The total ion intensity images (TII) shown for both concentrations are very different. For the $10^{-1}$ mol.L $\mathrm{L}^{-1}$ sample, a heterogeneous behavior is observed with the presence of highly bright areas (Figure 2a). In contrast, the TI image appears relatively homogeneous (Figure $2 \mathrm{~d}$ ) for the $10^{-3}$ mol.L ${ }^{-1}$ sample. For this image, the smooth brightness variation comes from a nonuniform efficiency of the detector. To get rid of this artifact for the specific ion images (Figure $2 b-f$ ), the intensity at each pixel is normalized with division by the TII. The $\mathrm{Si}^{+}$ion image (Figure $2 b$ ) shows the same contrast as the one seen in the total ion image (Figure 2a). This reveals surface micro-regions that are not covered by $\mathrm{Cr}(\mathrm{acac})_{3}$. This is confirmed by the negative contrast seen on the $\mathrm{L}_{3} \mathrm{Cr}$ linked ion image (Figure 2c). Such nonuniformity is not observed for sample surface prepared with a less concentrated $\mathrm{Cr}(\mathrm{acac})_{3}$ solution (see in Figure $2 \mathrm{e}-\mathrm{f}$ ). The distribution of catalyst precursor may be assumed to be more homogeneous in these spin-coating conditions.

It would be surprising to observe areas free of $\mathrm{Cr}(\mathrm{acac})_{3}$ on supports prepared with the highest concentration of the precursor solution. SEM measurements indicate an elevated roughness of the surface in that case [14]. The high concentration of the precursor solution leads to the formation of crystallites at the surface during the spin coating process. Surface defects are thought to help in this crystallization. The growth of these crystallites depletes the neighboring $\mathrm{Cr}(\mathrm{acac})_{3}$ precursor. Consequently, the $\mathrm{Si} / \mathrm{SiO}_{2}$ substrate ion emission increases in these depleted regions at the expense of $\mathrm{Cr}(\mathrm{acac})_{3}$ ions. This explains the increase of the brightness observed around $\mathrm{Cr}(\mathrm{acac})_{3}$ crystallites in the Figure 2a image.

According to surface segregation observed with 


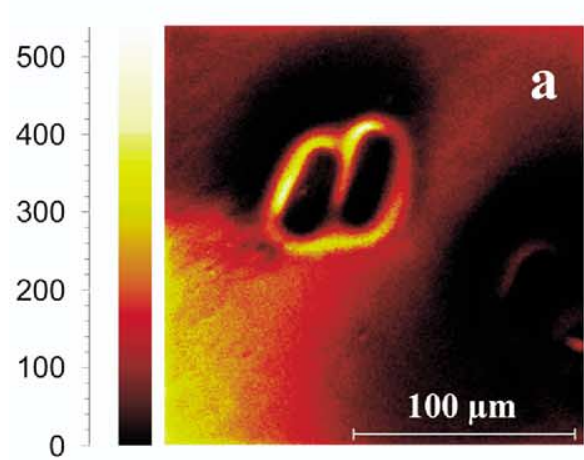

Total Ion Intensity (TII)

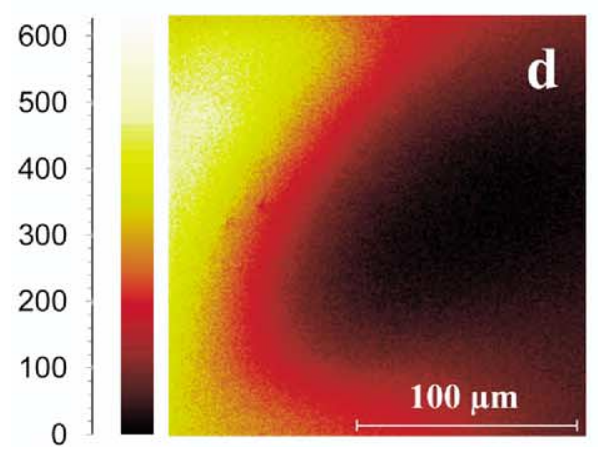

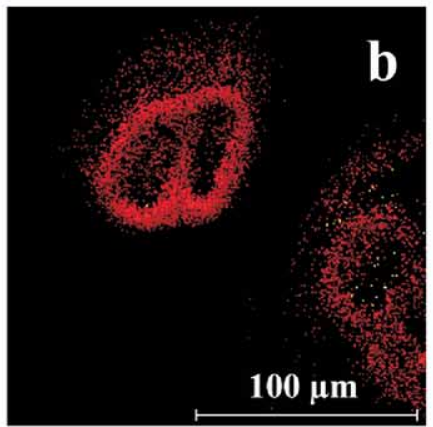

$\mathrm{Si}^{+} / \mathrm{TII}$

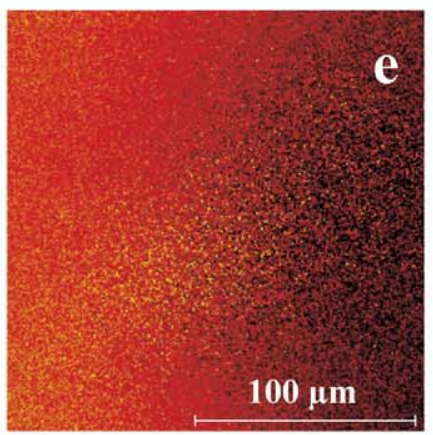

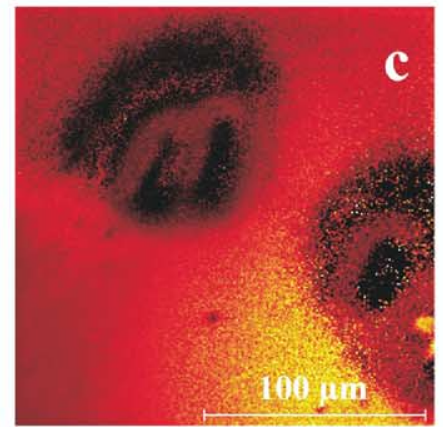

\section{$\Sigma\left(\mathrm{L}_{3} \mathrm{Cr}\right)$ linked cations/TII}

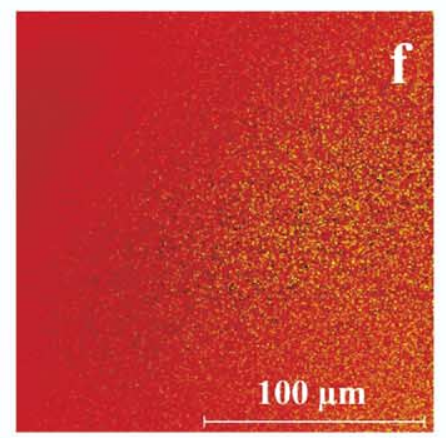

Figure 2. Positive precursor surface TOF-SIMS imaging. Samples are prepared by spin coating $\mathrm{Cr}(\mathrm{acac})_{3}$ solution in THF solution at $10^{-1}$ (top) or $10^{-3}$ (bottom) $\mathrm{mol} / \mathrm{L}$. TOF-SIMS images $(256 \times 256$ pixels) are acquired with a primary ion beam rastered over a $190 \times 190 \mu \mathrm{m}^{2}$ area of the sample for $1800 \mathrm{~s}$, which corresponds to an ion fluence close to $10^{12}$ ions $/ \mathrm{cm}^{2}$. Color scale are only relative to total ion intensity of (a) and (d) images. Maximum counts (mc) and total counts (tc) are equal to 538 and 7158,318 , respectively, for the (a) image and to 627 and 12,767,899 for the (d) image.

higher $\mathrm{Cr}(\mathrm{acac})_{3}$ concentrations, the activation step is conducted with substrates cast with a $10^{-3}$ mol. $\mathrm{L}^{-1}$ $\mathrm{Cr}(\mathrm{acac})_{3}$ precursor solution.

\section{Activation of Model Catalyst}

Here, the evolution of the molecular composition at the surface of the model catalyst is investigated by s-SIMS as a function of the thermal treatment temperature. Figure 3 shows the negative TOF-SIMS spectrum of the surface activated at the $350{ }^{\circ} \mathrm{C}$. The intensity of the ions associated with the $\mathrm{Cr}(\mathrm{acac})_{3}$ precursor is becoming very low. In contrast, cluster ions associating oxygen atoms with silicon and/or chromium ones are detected. Indeed, $\mathrm{SiO}_{2-3}{ }^{-}$and $\mathrm{HSiO}_{3}{ }^{-}$are detected at $\mathrm{m} / \mathrm{z}$ 60, 76 and 77; $\mathrm{CrO}_{2-3}{ }^{-}, \mathrm{Cr}_{2} \mathrm{O}_{4-6}{ }^{-}$, and $\mathrm{Cr}_{3} \mathrm{O}_{5-7}{ }^{-}$at $\mathrm{m} / \mathrm{z}$ 84, 100, $168,184,200,236,252,268$, and $\mathrm{SiCrO}_{4-5}{ }^{-}$at $\mathrm{m} / \mathrm{z} 144$ and 160 , respectively. Figure 4 presents the relative s-SIMS intensity evolutions as a function of the activation temperature. The secondary ions are gathered into four different groups. The first group concerns ions coming from the substrate $\left(\mathrm{SiO}_{2-3}{ }^{-}\right.$and $\mathrm{HSiO}_{3}{ }^{-}$species). The second group is associated with ions coming from the precursor compound. Third and fourth groups are correlated to oxygenated chromium and mixed oxygenated chromium-silicon compounds, respectively. For temperatures in the $150-350{ }^{\circ} \mathrm{C}$ range, the relative intensity of $\mathrm{Cr}(\mathrm{acac})_{3}$ linked ions dramatically decreases with the temperature increase, indicating the degrada-

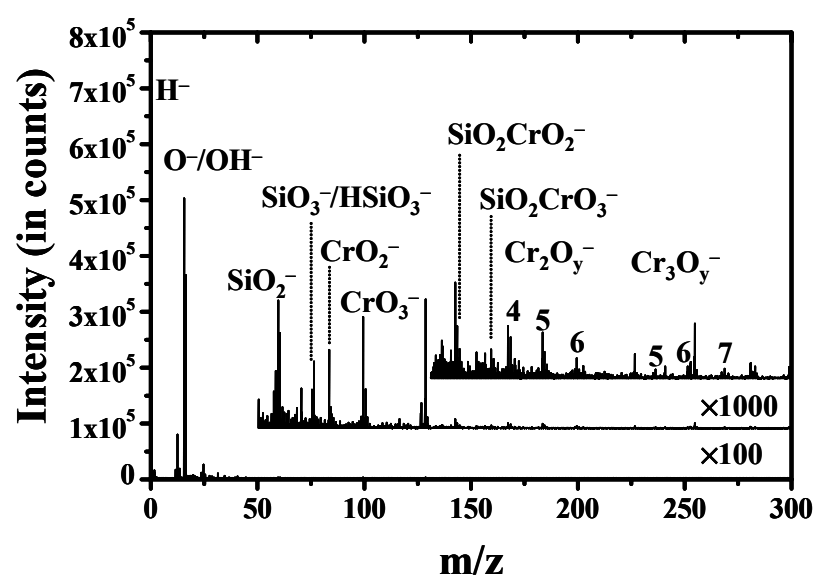

Figure 3. Negative TOF-SIMS spectrum of the model catalyst activated at $350{ }^{\circ} \mathrm{C}$ under dry air atmosphere. 


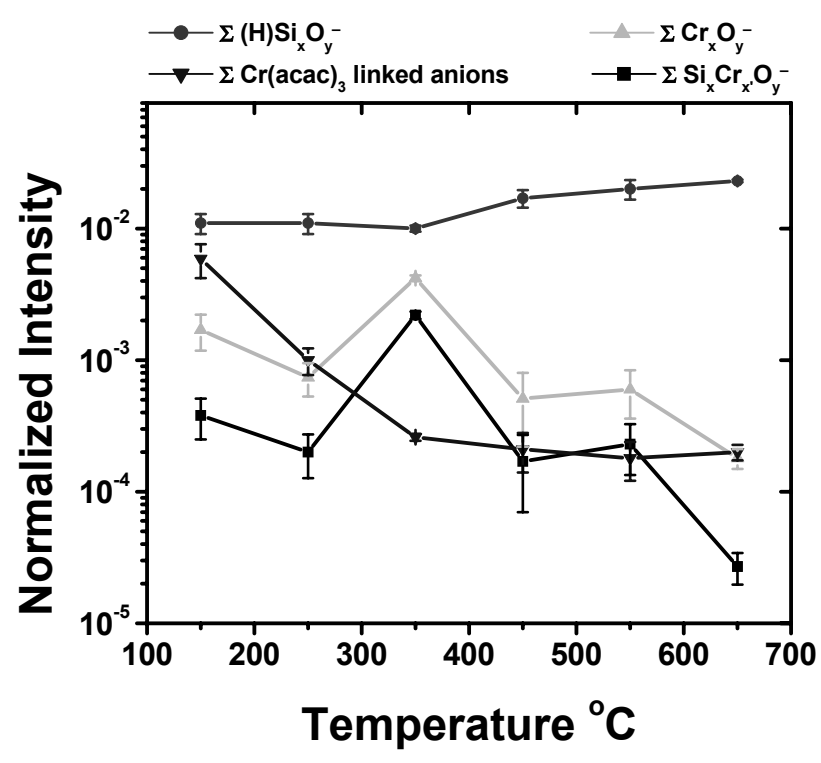

Figure 4. Development of negative ions observed by TOF-SIMS on model catalyst as a function of activation temperature under dry air atmosphere.

tion of precursor compound. In contrast, the normalized signals associated with $\mathrm{Cr}_{\mathrm{x}} \mathrm{O}_{\mathrm{y}}{ }^{-}$and $\mathrm{Si}_{\mathrm{x}} \mathrm{Cr}_{\mathrm{x}^{\prime}} \mathrm{O}_{\mathrm{y}}{ }^{-}$ions increase with the temperature up to a maximum, and then exhibit a decrease. A stable, normalized signal associated with the substrate is observed up to $350{ }^{\circ} \mathrm{C}$. For higher temperatures, the normalized intensity of ( $\mathrm{H}) \mathrm{Si}_{\mathrm{x}} \mathrm{O}_{\mathrm{y}}{ }^{-}$increases significantly, whereas the normalized abundance of anions containing chromium dramatically decreases.

These trends confirm previous results [15]. In addition, positive LDI-FTICRMS analysis allowed us to obtain complementary information on the $\mathrm{Cr}(\mathrm{acac})_{3}$ thermal degradation. Indeed, ions are more specifically detected at $m / z 135,179$, and 223, and they are assigned to $\left[\mathrm{C}_{5} \mathrm{H}_{11} \mathrm{O}_{4}\right]^{+},\left[\mathrm{C}_{11} \mathrm{H}_{15} \mathrm{O}_{2}\right]^{+}$, and $\left[\mathrm{C}_{13} \mathrm{H}_{19} \mathrm{O}_{3}\right]^{+}$, respectively. Two latter ions are pyrolysis products of the three acac ligands of $\mathrm{Cr}(\mathrm{acac})_{3}$. The $\mathrm{m} / \mathrm{z} 179$ and 223 ions could be associated with the loss of carbon dioxide, formaldehyde, and acetaldehyde molecules from the acac 3 trimer. Thus, $\left[\mathrm{C}_{11} \mathrm{H}_{15} \mathrm{O}_{2}\right]^{+}$and $\left[\mathrm{C}_{13} \mathrm{H}_{19} \mathrm{O}_{3}\right]^{+}$ions correspond to $\left[\mathrm{acac}_{3}-\mathrm{CO}_{2}-\mathrm{H}_{2} \mathrm{CO}-\mathrm{CH}_{3} \mathrm{CHO}\right]^{+}$and $\left[\mathrm{acac}_{3}-\mathrm{CO}_{2}-\mathrm{H}_{2} \mathrm{CO}\right]^{+}$species, respectively.

The degradation of the acac ligands appears to be complete at $350{ }^{\circ} \mathrm{C}$ according to the s-SIMS results. Simultaneously, the increase of normalized intensity of oxygenated chromium $\left(\mathrm{CrO}_{2-3}{ }^{-}, \mathrm{Cr}_{2} \mathrm{O}_{4-6}{ }^{-}\right.$, and $\left.\mathrm{Cr}_{3} \mathrm{O}_{5-7}{ }^{-}\right)$clusters highlights the formation of new chromium compounds. Indeed, the thermolysis of supported chromium complex in an oxidative atmosphere is known to form chromium oxides [23]. The relative distribution of chromium oxygenated anions observed by both mass spectrometry techniques at the $350{ }^{\circ} \mathrm{C}$ temperature is in accordance with the formation of $\mathrm{Cr}(\mathrm{VI})$ compounds. This information is obtained by applying the methodologies of chromium valence state identification previously reported in literature for s-SIMS [20] and for LA-MS [21] measurements. The destruction of the $\mathrm{Cr}(\mathrm{acac})_{3}$ precursor is therefore associated with the oxidation of $\mathrm{Cr}(\mathrm{III})$ compounds into $\mathrm{Cr}(\mathrm{VI})$ ones. The observation of mixed silicon-chromium-oxygen species by s-SIMS and LA-MS indicates a strong interaction between the substrate and the chromium compounds. Recombinations in the gas phase could also be evoked for the production of such ions by LA-MS but not for s-SIMS as recently reported [24]. Therefore, the detection of Si$\mathrm{CrO}_{4-5}{ }^{-}$anions by s-SIMS technique indicates the formation of mixed silicon-chromium species during the activation process. This illustrates the anchorage of chromium oxidized species by reaction with the hydroxyl groups of silica surface $[5,25,26]$.

The decrease of $\mathrm{Cr}_{2-3} \mathrm{O}_{4-7}{ }^{-}$and $\mathrm{SiCrO}_{4-5}{ }^{-}$s-SIMS normalized intensity for temperature higher than $350{ }^{\circ} \mathrm{C}$ is correlated with the increase of the relative intensity of silica linked ions as reported in Figure 4. This is explained by the desorption of a large part of the previously anchored chromium species. Indeed, cluster chromium oxygenated anions are more specifically removed from the surface for temperature greater than $350{ }^{\circ} \mathrm{C}$ as shown by Thüne et al. [12, 27]. For these authors, only chromate species are stable on the silica surface at high temperature [27].

According to the detection of highly oxygenated hydrocarbon compounds by LDI-MS, the destruction of $\mathrm{Cr}(\mathrm{acac})_{3}$ compound by thermal treatment occurs in the same time that recombination and/or pyrolysis processes, and oxidation of $\mathrm{Cr}(\mathrm{III})$ into $\mathrm{Cr}(\mathrm{VI})$.

\section{Efficiency of Activated Model Catalyst for Ethylene Polymerization}

Here, the surface of model catalyst after ethylene polymerization is investigated by both TOF-SIMS and TOFLDI-MS techniques. The static TOF-SIMS mass spectrum of polymerized ethylene is presented in Figure 5. In standard analytical conditions, i.e., without $6 \times 10^{14}$ ${ }^{69} \mathrm{Ga}^{+} / \mathrm{cm}^{2}$ sputtering before analysis, typical $\mathrm{C}_{\mathrm{n}} \mathrm{H}_{\mathrm{m}}{ }^{+}$ hydrocarbon peaks are observed (not shown). After cleaning by $6 \times 10^{14}{ }^{69} \mathrm{Ga}^{+} / \mathrm{cm}^{2}$ sputtering, the spectrum still exhibits $\mathrm{C}_{\mathrm{n}} \mathrm{H}_{\mathrm{m}}{ }^{+}$fragments, as seen in Figure 5. These fragments at $m / z 41,43,55,57,69,71,91,105,117$, 128 , and 141 are typical fingerprints for polyethylene [28, 29].

We previously reported the LDI mass spectrum of the model catalyst after ethylene polymerization [15]. The mass spectrum displays a pseudo-oligomeric polymer molecular weight distribution in the $\mathrm{m} / \mathrm{z} 400-850$ range. The ions are ascribed to the general $\left[\mathrm{CH}_{3}\left(\mathrm{C}_{2} \mathrm{H}_{4}\right)_{\mathrm{n}}\left(\mathrm{CH}_{2}\right)_{\mathrm{m}}\left(\mathrm{C}_{2} \mathrm{H}_{2}\right)_{\mathrm{p}}\left(\mathrm{C}_{2} \mathrm{H}_{2}\right)\right]^{+}$formulae. The number of insaturations, i.e., the number $\mathrm{p}$, is seen to decrease when the hydrocarbon chain length increases.

Complementary analyses [14, 15] by AFM and FTIR well identify the formed polymer as crystalline polyethylene and confirm s-SIMS and LDI-MS analyses. The insaturations observed in species detected by mass spectrom- 

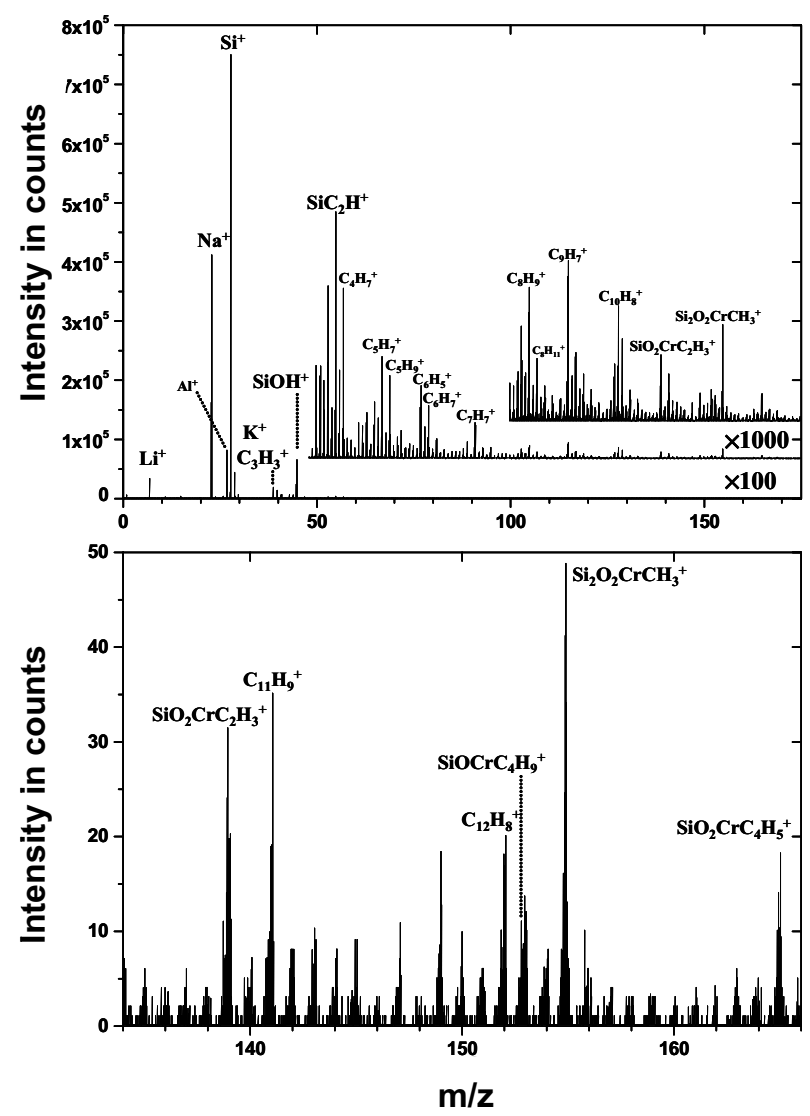

Figure 5. TOF-SIMS mass spectra of activated model catalyst after ethylene polymerization. A presputtering with a ${ }^{69} \mathrm{Ga}^{+}$ion dose of $6 \times 10^{14}{ }^{69} \mathrm{Ga}^{+} / \mathrm{cm}^{2}$ prior analysis. Bottom spectrum is a magnification of top spectrum in the $134-164 \mathrm{~m} / \mathrm{z}$ range.

etry may result from UV laser irradiation, reorganizations of hydrocarbon chains, or from the polymerization process itself, as previously discussed [15].

\section{Characterization of a Real Phillips Catalyst}

Here, LA-FTICRMS is used to characterize the real Phillips catalyst. The influence of the laser irradiance in the $4 \times 10^{10}-5 \times 10^{7} \mathrm{~W} / \mathrm{cm}^{2}$ range is first investigated in the study of fresh, activated, and reduced catalysts. Our attention is focused on the negative ions, which provide the more significant information. For fresh catalyst, the following ions are specifically detected at high irradiance: $\mathrm{Cr}_{\mathrm{x}} \mathrm{O}_{\mathrm{y}}{ }^{-}$and $\left(\mathrm{SiO}_{2}\right)_{\mathrm{n}} \mathrm{X}^{-}$cluster ions with $\mathrm{X}=\mathrm{OH}, \mathrm{SiO}_{2}, \mathrm{SiO}_{3}, \mathrm{CrO}_{2}$ and $\mathrm{CrO}_{3}$. The distribution of these ions (not shown) is very close to what it is observed for the impregnated model catalyst when it is studied by LA-FTICRMS [15]. Ions linked to acac ligand are only poorly detected in these experimental conditions. When the laser irradiance decreases down to $5 \times$ $10^{7} \mathrm{~W} / \mathrm{cm}^{2}$, the signal dramatically decreases and disappears (see in Figure 6a). More specifically, ions associated with $\mathrm{Cr}(\mathrm{acac})_{3}$ or oxygenated chromium cluster anions are not observed anymore.

After activation (Figure 6b), the analysis with an irradiance of $5 \times 10^{7} \mathrm{~W} / \mathrm{cm}^{2}$ shows chromium oxygenated species as well as mixed chromium-silicon oxygenated anions. The observed mass spectra are very close to the recorded data for the activated model catalyst by LA-FTICRMS [15] or s-SIMS (Figure 3). After reduction in hydrogen atmosphere for $2 \mathrm{~h}$, the intensity of large oxygenated cluster anions (containing chromium and mixed chromium-silicon) dramatically decreases (Figure $6 \mathrm{c}$ ). This behavior is associated with a modification of the cluster ion distribution, showing a dramatic decrease for the oxygenated species. As examples, see the modification in the relative intensity for $\mathrm{SiO}_{2} \mathrm{CrO}_{2}{ }^{-}$, $\mathrm{SiO}_{2} \mathrm{CrO}_{3}{ }^{-}, \mathrm{Cr}_{2} \mathrm{O}_{4}{ }^{-}, \mathrm{Cr}_{2} \mathrm{O}_{5}{ }^{-}$, and $\mathrm{Cr}_{2} \mathrm{O}_{6}{ }^{-}$ions.

To evaluate the oxidation state of chromium for activated and reduced real Philips catalyst, the methodology of chromium chemical state identification, we recently published [21], and applied in the investigation of pollutants in dust particles [30] is used. This methodology has been tested with various matrices and supports: note that this methodology is also applicable for powder [21]. Experiments have to be conducted at the $355 \mathrm{~nm}$ wavelength. Under these experimental conditions, the obtained mass spectra for activated and
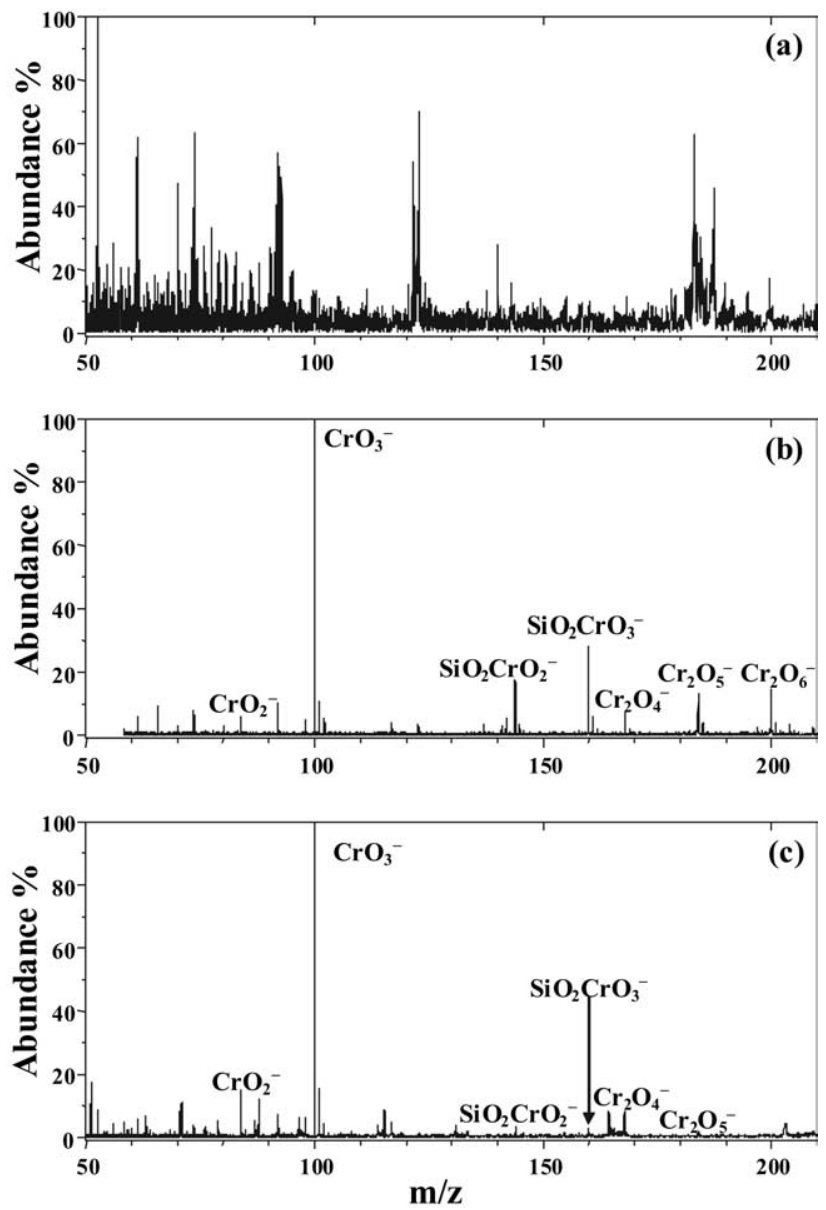

Figure 6. Analysis of a real Phillips catalyst after (a) precursor impregnation, (b) activation, and (c) reduction. Experiments are conducted by LA-FTICRMS at the 283.6 wavelength with a power density of $5 \times 10^{7}$ W.cm ${ }^{-1}$. 
<smiles>C=CC(=O)O[Si]</smiles>

$m / z 139$

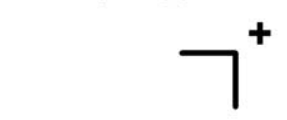<smiles>C[C](O[SiH3])O[SiH3]</smiles>

$m / z 155$

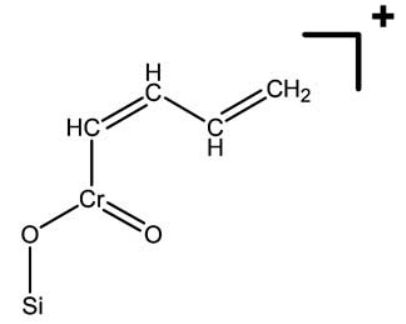

$m / z 165$

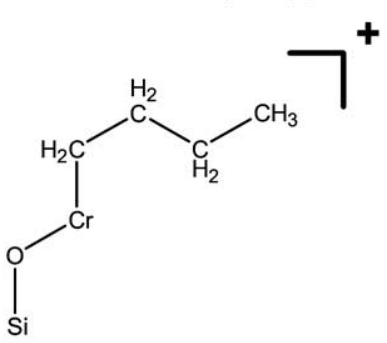

$m / z 153$
Figure 7. Proposed structures for hybrid organic-inorganic ions detected by s-SIMS analysis of model catalysis after ethylene polymerization.

reduced real catalysts are very similar to what is observed in Figure $6 \mathrm{~b}$ and $\mathrm{c}$ at the $283.6 \mathrm{~nm}$ wavelength. Depending on the ion intensity ratio $\mathrm{R}=\mathrm{Cr}_{2} \mathrm{O}_{4}{ }^{-}$/ $\mathrm{Cr}_{2} \mathrm{O}_{6}{ }^{-}$trivalent and hexavalent chromium compounds can be distinguished. $\mathrm{R}$ is lower than 0.5 for $\mathrm{Cr}$ (VI) compounds and greater than 0.8 for $\mathrm{Cr}$ (III) ones. For activated catalyst $\mathrm{R}$ is equal to 0.48 . The $\mathrm{Cr}_{2} \mathrm{O}_{6}{ }^{-}$ion is not detected significantly in the study of the reduced catalyst. It could therefore be assumed that this ratio is for the most part greater than 1. Consequently, it may be argued that $\mathrm{Cr}(\mathrm{VI})$ is present at the surface of the activated catalyst. The examination of chromium valence at the surface of reduced catalyst is more difficult. Whatever the standard $\mathrm{Cr}$ (III) compounds used to establish our methodology of chromium chemical state differentiation [21], the $\mathrm{Cr}_{2} \mathrm{O}_{6}{ }^{-}$ion is detected. Consequently, it is reasonable to consider that chromium present at the surface of reduced catalyst is bivalent rather than trivalent. The $\mathrm{CrO}_{2}{ }^{-} / \mathrm{CrO}_{3}{ }^{-}$ion intensity ratio confirms this conclusion; it is greater than what is observed for the investigated $\mathrm{Cr}(\mathrm{III})$ compounds in reference [21]. The anchorage of $\mathrm{Cr}(\mathrm{VI})$ for activated catalyst and $\mathrm{Cr}(\mathrm{II})$ for the reduced one is proven by the detection of mixed chromium-silicon-oxygen species.

\section{Mechanism of Ethylene Polymerization}

In addition to hydrocarbon ions display in Figure 5, hybrid organic-inorganic species are also detected by s-SIMS at $m / z 139,153,155$, and 165 . They are assigned to $\left[\mathrm{SiO}_{2} \mathrm{CrC}_{2} \mathrm{H}_{3}\right]^{+},\left[\mathrm{Si}_{2} \mathrm{O}_{2} \mathrm{CrCH}_{3}\right]^{+},\left[\mathrm{SiOCrC}_{4} \mathrm{H}_{9}\right]^{+}$, and $\left[\mathrm{SiO}_{2} \mathrm{CrC}_{4} \mathrm{H}_{5}\right]^{+}$ions, respectively. The structure of these mixed ions is proposed in Figure 7. These ions could be rationalized by considering the fixation of fragments or small hydrocarbon chains on chromium atoms anchored on catalyst substrate. Both saturated and unsaturated compounds appear to be associated with these ions. The $\mathrm{m} / z 139$ ion seems to indicate the ethylene fixation on anchored chromium oxides. The addition of a second monomer leads to the observation of the $\mathrm{m} / \mathrm{z}$ 165 ion. The removal of the carbon unsaturation appears to be associated with a reduction of the chromium valence, see $m / z 153$ ion. Consequently, ethylene apparently requires the chromium to be bivalent or trivalent in order to be fixed on the catalyst active site. The growth of polyethylene seems to be associated with the presence of bivalent chromium compounds at the model catalyst surface. These findings agree with the previously proposed mechanisms [1, 31-34]. Moreover, it is known that aldehyde could by formed during ethylene polymeration [1]. In this respect, $m / z 139$ and 165 ions could also be considered as an association of $\mathrm{Cr}(\mathrm{II})$ with formaldehyde or acetaldehyde.

\section{References}

1. McDaniel, M. P. Supported Chromium Catalysts for Ethylene Polymerization. Adv. Catal. 1985, 33, 47-98.

2. Weckhuysen, B. M.; Wachs, I. E.; Schoonheydt, R. A. Surface Chemistry and Spectroscopy of Chromium in Inorganic Oxides. Chem. Rev. 1996, 96, 3327-3350.

3. Hogan, J. P.; Norwood, D. D.; Ayres, C. A. Phillips Petroleum Company Loop Reactor Polyethylene Technology. J. Appl. Polym. Sci. Appl. Polym. 1981, 36, 49-64.

4. Groppo, E.; Lamberti, C.; Bordiga, S.; Spoto, G.; Zecchina, A. The Structure of Active Centers and the Ethylene Polymerization Mechanism on the $\mathrm{Cr} / \mathrm{SiO}_{2}$ Catalyst: A Frontier for the Characterization Methods. Chem. Rev. 2005, 105, 115-183.

5. McDaniel, M. P.; Welch, M. B. The Activation of the Phillips Polymerization Catalyst: I. Influence of the Hydroxyl Population. J. Catal. 1983, 82, 98-109.

6. McDaniel, M. P. The State of Chromium (VI) on the Chromium/Silica Polymerization Catalyst. J. Catal. 1981, 67, 71-76.

7. Myers, D. L.; Lunsford, J. H. Silica-Supported Chromium Catalysts for Ethylene Polymerization. J. Catal. 1985, 92, 260-271.

8. Weckhuysen, B. M.; Schoonheydt, R. A. Olefin Polymerization Over Supported Chromium Oxide Catalysts. Catal. Today 1999, 51, 215-221.

9. Weist, E. L.; Ali, A. H.; Conner, W. C. Morphological Study of Supported Chromium Polymerization Catalysts. 1. Activation. Macromolecules 1987, 20, 689-693.

10. Thüne, P. C.; Verhagen, C. P. J.; van den Boer, M. J. G.; Niemantsverdriet, J. W. Working Surface Science Model for the Phillips Ethylene Polymerization Catalyst: Preparation and Testing. J. Phys. Chem. B 1997, 101, 8559-8563.

11. Thune, P. C.; Loos, J.; Lemstra, P. J.; Niemantsverdriet, J. W. Polyethylene Formation on a Planar Surface Science Model of a Chromium Oxide Polymerization Catalyst. J. Catal. 1999, 183, 1-5.

12. Thüne, P. C.; Linke, R.; van Gennip, W. J. H.; de Jong, A. M.; Niemantsverdriet, J. W. Bonding of Supported Chromium during Thermal Activation of the $\mathrm{CrO}_{x} / \mathrm{SiO}_{2}$ (Phillips) Ethylene Polymerization Catalyst. J. Phys. Chem. B 2001, 105, 3073-3078.

13. Loos, J.; Thüne, P. C.; Niemantsverdriet, J. W. Polymerization and Crystallization of Polyethylene on a Flat Model Catalyst. Macromolecules 1999, 32, 8910-8913.

14. Di Croce, P. G.; Aubriet, F.; Bertrand, P.; Rouxhet, P.; Grange P. Elaboration and Characterization of a Model Phillips Catalyst for Ethylene Polymerization. Stud. Surf. Sci. 2002, 143, 754-758.

15. Di Croce, P. G.; Aubriet, F.; Chety-Gimondo, R.; Muller, J.-F.; Grange P. Characterization of a Model Phillips Catalyst by Mass Spectrometry. Rapid Commun. Mass Spectrom. 2004, 18, 601-608.

16. Pierce, J. L.; Busch, K. L.; Cooks, R. G.; Walton, R. A. Desorption Ionization Mass Spectrometry: Secondary Ion and Laser Desorption Mass Spectra of Transition-Metal Complexes of b-Diketones. Inorg. Chem. 1982, 21, 2597-2602.

17. Bartlett, M. G.; Haas, G. M.; Bruce, D. A.; Thomas, S. M.; White, M. G.; Bertrand, J. A.; Busch, K. L.Characterization of Supported and Unsupported Transition Metal Compounds by Liquid Secondary Ion Mass Spectrometry.Anal. Chim. Acta 1997, 346, 223-236.

18. Matsumoto, K.; Ajiro, H.; Habaue, S.; Okamoto, Y. Detection of Solid Cobalt Species by Matrix-Assisted Laser Desorption/Ionization Time- 
of-Flight Mass Spectrometry. Rapid Commun. Mass Spectrom. 2002, 16, 730-732.

19. Matsumoto, K.; Ajiro, H.; Habaue, S.; Okamoto, Y. Detection of Inorganic Species by Chemical Reaction Laser Desorption Ionization Mass Spectrometry. Rapid Commun. Mass Spectrom. 2003, 17, 678-684.

20. Aubriet, F.; Poleunis, C.; Bertrand, P. Capabilities of Static TOF-SIMS in the Differentiation of First-Row Transition Metal Oxides. J. Mass Spectrom. 2001, 36, 641-651.

21. Aubriet, F.; Maunit, B.; Muller, J.-F. Speciation of Chromium Compounds by Laser Ablation/Ionization Mass Spectrometry and a Study of Matrix Effects. Int. J. Mass Spectrom. 2001, 209, 5-21.

22. Aubriet F.; Vernex-Loset L.; Maunit B.; Krier G.; Muller J. F. The Resonance Laser Ablation Fourier Transform Ion Cyclotron Resonance Mass Spectrometry (RLA-FTICRMS) a New Coupling for Material Science. Int. J. Mass Spectrom. 2002, 219, 717-727.

23. Van Der Voort, P.; Possemiers, K.; Vansant, E. F. Preparation of supported vanadium oxide catalysts. Adsorption and Thermolysis of Vanadyl Acetylacetonate on a Silica Support. J. Chem. Soc. Faraday Trans. 1996, 92, 843-848.

24. Aubriet, F.; Poleunis, C.; Chaoui, N.; Maunit, B.; Millon, E.; Muller, J.-F.; Bertrand, P. Laser Ablation and Static Secondary Ion Mass Spectrometry Capabilities in the Characterization of Inorganic Materials. Appl. Surf. Sci. 2002, 186, 315-321.

25. Babich, I. V.; Plyuto, Y. V.; Van Der Voort, P.; Vansant, E. F. Thermal Transformations of Chromium Acetylacetonate on Silica Surface. I. Colloid. Interface Sci. 1997, 189, 144-150.
26. Hakuli, A.; Kytökivi, A. Binding of Chromium Acetylacetonate on a Silica Support. Phys. Chem. Chem. Phys. 1999, 1, 1607-1613.

27. Thüne, P. C.; Loos, J.; Wouters, D.; Lemstra, P. J.; Niemantsverdriet, J. W. The $\mathrm{CrO}_{x} / \mathrm{SiO}_{2} / \mathrm{Si}(100)$ Catalyst-A Surface Science Approach to Supported Olefin Polymerization Catalysis. Macromol. Symp. 2001, 173, 37-52.

28. Galuska, A. A. Quantitative Surface Analysis of Ethylene-Propylene Polymers Using TOF-SIMS. Surf. Interface Anal. 1997, 25, 1-4.

29. Médard, N.; Aouinti, M.; Poncin-Epaillard, F.; Bertrand, P. TOF-SIMS Ability to Quantify Surface Chemical Groups: Correlation with XPS Analysis and Spectrochemical Titration. Surf. Interface Anal. 2001, 31, 1042-1047.

30. Carré, V.; Aubriet, F.; Scheepers, P. T.; Krier, G.; Muller, J.-F. Potential of Laser Ablation and Laser Desorption Mass Spectrometry to Characterize Organic and Inorganic Environmental Pollutants on Dust Particles. Rapid Commun. Mass Spectrom. 2005, 19, 871-880.

31. Merryfield, R.; McDaniel, M.; Parks, G. An XPS Study of the Phillips Cr/Silica Polymerization Catalyst. 1982, 77, 348-359.

32. Baker, L. M.; Carrick, W. L. Oxidation of Olefins by Supported Chromium Oxide. J. Org. Chem. 1968, 33, 616-618.

33. Liu, B.; Nakatani, H.; Terano, M. New Aspects of the Induction Period of Ethene Polymerization Using Phillips $\mathrm{CrO}_{x} / \mathrm{SiO}_{2}$ Catalyst Probed by XPS, TPD, and EPMA. J. Mol. Catal. A 2002, 184, 387-398.

34. Choi, K. Y.; Tang, S. H. Polymerization Rate Modeling of Ethylene Polymerization with Supported Chromium Oxide Catalysts. J. Appl. Polym. Sci. 2004, 91, 2923-2927. 